\title{
Micro- and Nanostripes of Self-Assembled Au Nanocrystal Superlattices by Direct Micromolding
}

\author{
Boya Radha and Giridhar U. Kulkarni ( $\square)$ \\ Chemistry and Physics of Materials Unit and DST Unit on Nanoscience, Jawaharlal Nehru Centre for Advanced Scientific Research, Jakkur \\ P.O., Bangalore 560064, India \\ Received: 13 May 2010 / Accepted: 8 June 2010 \\ (C) The Author(s) 2010. This article is published with open access at Springerlink.com
}

\begin{abstract}
A simple, inexpensive direct micromolding method for patterning Au nanocrystal superlattices using a polydimethylsiloxane (PDMS) stamp has been developed. The method involves in situ synthesis of $\mathrm{Au}(\mathrm{I})$ dodecanethiolate and its decomposition leading to Au nanocrystals in the microchannels of the stamp which order themselves to form patterned superlattice stripes, in conformity with the stamp geometry. Owing to its insolubility in common solvents, the dodecanethiolate was made by reacting $\mathrm{Au}\left(\mathrm{PPh}_{3}\right) \mathrm{Cl}$ and dodecanethiol in situ inside the microchannels, by injecting first the former solution in toluene at room temperature followed by the thiol solution at $120^{\circ} \mathrm{C}$. Annealing the reaction mixture at $250{ }^{\circ} \mathrm{C}$, resulted in formation of nanocrystals (with a mean diameter of $7.5 \mathrm{~nm}$ ) and hexagonal ordering. By using an external pressure while molding, parallel stripes with sub-100 nm widths were obtained. The choice of parameters such as injection temperature of the thiol and concentrations is shown to be important if an ordered superlattice is to be obtained. In addition, these parameters can be varied as a means to control the nanocrystal size.
\end{abstract}

\section{KEYWORDS}

nanolithography, soft lithography, metal nanocrystal superlattice, micromolding, direct patterning

\section{Introduction}

In an ordered arrangement of metal nanocrystals, there exist emergent collective properties besides the properties possessed by the individual nanocrystals $[1,2]$. It is therefore not surprising that mesoscalar lattices of nanocrystals have attracted a great deal of attention [3]. While the properties of individual nanocrystals are tuned by varying the size, the collective properties - such as optical, electronic, and magnetic - are influenced not only by the nanocrystal size but also by the interparticle separation and the nature of the spacer ligands [4-6]. These parameters have been tailored for designing high density data storage [7], nanoscale interconnects [8, 9], and tunable optical elements [10]. Many interesting phenomena and processes such as single electron transport [11], metal-insulator transitions [12,13], and magnetic transitions $[7,14]$ have been revisited at the mesoscale using nanocrystal arrays as model systems. Besides two-dimensional (2-D) arrays, linear (1-D) assemblies [15] as well as three-dimensional (3-D) assemblies of nanocrystals (supracrystals) $[16,17]$ have also been fabricated.

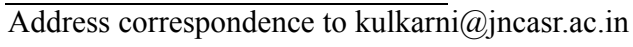


Selectively positioning and addressing bits containing individual nanocrystals or arrays is of paramount importance in device applications. Towards this end, various lithography techniques have been employed for patterning stripe or dot features containing spontaneously organized nanocrystals. For instance, Hamann et al. obtained patterned mesodots of FePt nanocrystals by shining a laser beam though a mask onto a nanocrystal film [18]. Metal precursor loaded block copolymer micelles [19], Au(I) thiolate thin films [20, 21], thiolated $\mathrm{Au}$ [22], tetraoctylammonium bromide-capped Pd nanocrystal sols [23], and gold cluster compounds [24] have served as negative resists in ion or e-beam lithography to create mesoscale lattices of nanocrystals. Electrodynamic focusing of aerogels containing Ag nanocrystals has been employed to produce nanoparticle patterns on conducting and nonconducting surfaces [25]. Au nanoparticles embedded in micelles have been cast into nanopatterns via nanoimprint lithography [26]. Further, there are a set of soft lithography methods-microcontact printing of nanocrystals [27, 28] down to even single nanocrystal resolution [29], deprinting leading to selective lift-off of the precursor [30], controlled dewetting [31,32], molding of microdroplets of nanocrystal sols [33], and ways of deriving free-standing patches of nanoparticle superlattice [34] - which have been used for this purpose. As micromolding involves the simple steps of introducing an 'ink' into defined microchannels and evaporating the solvent, it is considered extremely efficient and therefore has been widely employed in patterning a variety of materials [35], particularly polymers [36]. However, employing micromolding methods to produce nanocrystal array patterns is a challenging task. This problem is clearly discussed in Ref. [33]. If one starts with a premade sol, the particle-particle and particle-substrate interactions dictate the organization, which is usually discontinuous over larger areas $[33,37,38]$. A recent report makes use of a mixture of high and low boiling solvents to exercise control over the nanocrystal organization in predefined channels [39]. Here, we report a simple method based on micromolding in capillaries where in situ synthesis, ordering as well as patterning of $\mathrm{Au}$ nanocrystals all take place in a single step. The choice with respect to the metal $(\mathrm{Au})$ was made considering its importance in many areas including chemical and biosensing, diagnostics, cellular imaging, plasmonic activity, ease of functionalization, and enhanced Raman scattering [40-42].

\section{Experimental section}

$\mathrm{Au}\left(\mathrm{PPh}_{3}\right) \mathrm{Cl}$ was synthesized based on a procedure reported in the literature (for details of the synthesis, please see the Electronic Supplementary Material (ESM)). Elastomeric stamps (10 mm wide) were fabricated by replica molding of polydimethylsiloxane (PDMS) on a commercially available compact disk (Sony CD-R). PDMS was prepared by mixing Sylgard 184 curing agent (Dow Corning) and its elastomer in the ratio of $1: 10$ by mass. The mixture was then degassed under vacuum for $30 \mathrm{~min}$. PDMS was poured onto the polycarbonate backing of the master (CD) and then cured in an oven at $70{ }^{\circ} \mathrm{C}$ overnight. The stamp peeled off from the master contained protruding line features with a width of $505 \mathrm{~nm}$ separated by $950 \mathrm{~nm}$ channels. The stamp was $\sim 2 \mathrm{~mm}$ thick and weighed $\sim 2.4$ grams. PDMS stamps were cleaned using hexane and sonicated in ethanol to remove any uncured, low molecular mass oligomers. Si(111) substrates (n-doped, $4-7 \Omega \cdot \mathrm{cm}$ ) were cleaned by sonicating in acetone and double-distilled water and dried under flowing argon. The patterned substrates were examined using a Nova NanoSEM 600 instrument (FEI Co., The Netherlands). Energy-dispersive spectroscopy (EDS) analysis was performed with an EDAX Genesis instrument (Mahwah, NJ) attached to the scanning electron microscope (SEM) column.

\section{Results and discussion}

Direct micromolding requires an appropriate metalorganic precursor, which decomposes cleanly to give rise to the metal (nanocrystals) at relatively low working temperatures. Its high solubility in common solvents is also crucial, as the micromolding process relies on capillary flow [36]. In one such attempt, we used $\mathrm{Au}\left(\mathrm{PPh}_{3}\right) \mathrm{Cl}$ in toluene $(1 \mathrm{mmol} / \mathrm{L})$ as a precursor ink. The X-ray diffraction (XRD) data from a film of the precursor (Fig. 1(a)) clearly shows the formation of polycrystalline Au upon heating in air to $250{ }^{\circ} \mathrm{C}$ (Fig. 1(b)). 


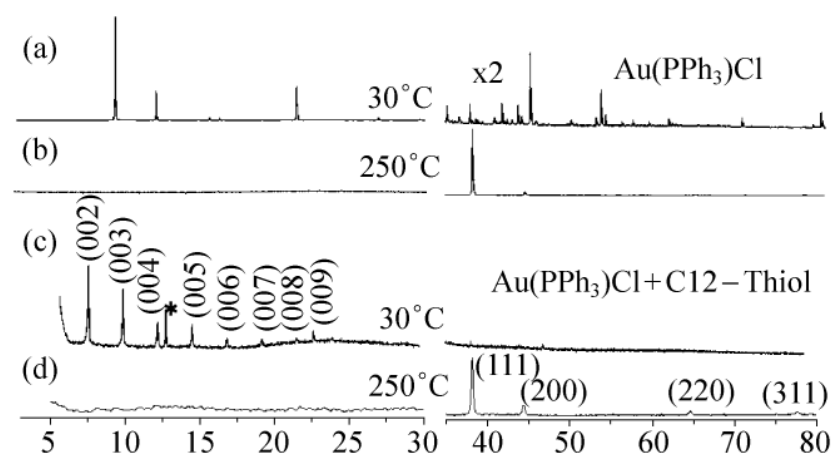

Figure 1 XRD data of $\mathrm{Au}\left(\mathrm{PPh}_{3}\right) \mathrm{Cl}$ drop-coated as a film (a) as prepared, and (b) after heating to $250{ }^{\circ} \mathrm{C}$; XRD data of a mixture of $\mathrm{Au}\left(\mathrm{PPh}_{3}\right) \mathrm{Cl}$ and dodecanethiol (c) as prepared and (d) after heating to $250{ }^{\circ} \mathrm{C}$, when the peaks are indexed by reference to the standard pattern for polycrystalline Au (JCPDS PDF No. 040784). Some precursor $\mathrm{Au}\left(\mathrm{PPh}_{3}\right) \mathrm{Cl}$ still remains in (c), as revealed by the peak marked by*

This is also supported by the TGA data (Fig. S-1 in the ESM). For micromolding, a topographically patterned
PDMS stamp placed on a $\mathrm{Si}$ substrate served as a mold for hosting microchannels as depicted in the scheme in Fig. 2(a). A $60 \mu \mathrm{L}$ aliquot of the $\mathrm{Au}\left(\mathrm{PPh}_{3}\right) \mathrm{Cl}$ solution was dropped at the stamp edge so as to fill the microchannels. The setup was heated gradually to $250{ }^{\circ} \mathrm{C}$ in steps of $10{ }^{\circ} \mathrm{C}$ per min and held for $30 \mathrm{~min}$. After cooling, the stamp was removed leaving behind the molded material with stripe patterns covering large areas. However, this procedure gave rise to $\mathrm{Au}$ nanocrystals with large size variation (Fig. 2(b)). Although the stripe patterning was evident (Fig. S-2 in the ESM), we were unable to obtain an ordered nanocrystal array based on this process. For example, a lower rate of heating $\left(5{ }^{\circ} \mathrm{C}\right.$ per min) offered no benefit (see Fig. S-3 in the ESM).

Metal alkanethiolates have been extensively used in nanocrystal preparations [43], despite their low solubility in common solvents [44]. We decided to carry out an in situ synthesis of a thiolate followed by

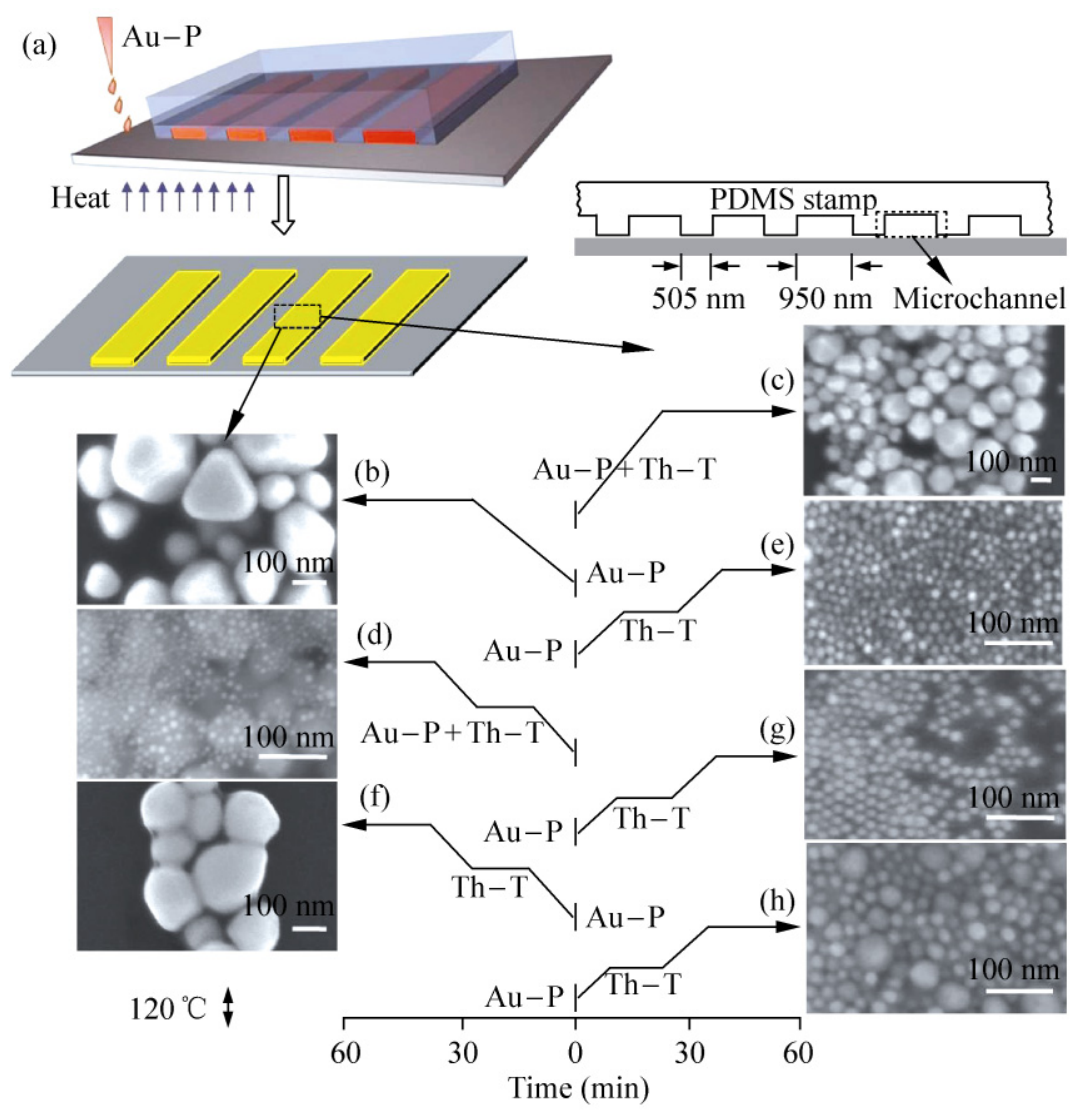

Figure 2 Direct patterning of Au nanocrystal superlattices by micromolding. (a) Schematic illustration showing introduction of the precursor inks at the interface of the PDMS stamp and the Si substrate, followed by thermolysis at $250{ }^{\circ} \mathrm{C}$. Stamp geometry is shown alongside. (b)-(h) SEM images showing Au nanocrystal arrays obtained by varying the preparation conditions as discussed in the text. $\mathrm{Au}\left(\mathrm{PPh}_{3}\right) \mathrm{Cl}=\mathrm{Au}-\mathrm{P} ; \mathrm{Th}=\mathrm{Thiol} ; \mathrm{T}=$ Toluene; Total reaction time was $60 \mathrm{~min}$ 
its decomposition, as thiolates are known to give rise to uniform sized Au nanocrystals upon thermolysis [45]. A simple mixing of $\mathrm{Au}\left(\mathrm{PPh}_{3}\right) \mathrm{Cl}$ and dodecanethiol solutions at room temperature leads to the formation of the $\mathrm{Au}(\mathrm{I})$-thiolate as shown in the XRD data in Fig. 1(c). When subjected to thermolysis at $250{ }^{\circ} \mathrm{C}$ in air, the corresponding XRD pattern (Fig. 1(d)) showed peaks corresponding to polycrystalline Au. Encouraged by this finding, we introduced mixed toluene solutions of $\mathrm{Au}\left(\mathrm{PPh}_{3}\right) \mathrm{Cl}$ and dodecanethiol $(1 \mathrm{mmol} / \mathrm{L}, 60 \mu \mathrm{L}$ each) into the stamp mold and heated it to $250{ }^{\circ} \mathrm{C}$ (Fig. 2(c)). Nanocrystals in the size range 50-100 nm were formed, with some indications of close packing, but there were voids between them. Mixing the ingredients prior to molding seems to accelerate the nanocrystal growth. Introducing the mixed solutions at $120{ }^{\circ} \mathrm{C}$ (slightly above the boiling point of the solvent, $110{ }^{\circ} \mathrm{C}$ ), gave rise to tiny $\mathrm{Au}$ nanocrystals (8-15 nm) amidst larger ones (50-100 nm) with little improvement in packing (Fig. 2(d)). This suggests that a sudden evaporation of the solvent may hold the key for small nanocrystal formation. Based on the above experiments, we resorted to a two-step synthesis-first introducing the $\mathrm{Au}\left(\mathrm{PPh}_{3}\right) \mathrm{Cl}$ solution into the mold at room temperature followed by the dodecanethiol solution at elevated temperatures (Figs. 2(e)-2(h)). This was followed by thermolysis at $250{ }^{\circ} \mathrm{C}$. The introduction of the thiol at $120^{\circ} \mathrm{C}$ gave rise to fine nanocrystals as seen Fig. 2(e), with more details shown in Fig. 3. The nanocrystal stripes can be seen over a large area (Fig. 3(a)) and the EDS spectrum showed the presence of $\mathrm{Au}$. The stripes measure $\sim 1.08 \mu \mathrm{m}$ across, corresponding to the microchannel width of $950 \mathrm{~nm}$ (see Fig. 2(a)). From Fig. 3(b), we can see that each stripe is essentially a colony of $\mathrm{Au}$ nanocrystals organized into a superlattice. The internal hexagonal ordering in the superlattice is evidenced from the magnified image shown in Fig. 3(c). Careful observation reveals the multilayer structure of the patterned stripe. SEM images from various locations on the patterned stripes (Fig. 3(a)) shown in Fig. S-4 in the ESM reveal the remarkable uniformity of the nanocrystal ordering. The fast Fourier transform of the hexagonal ordering is shown in Fig. S-5 in the ESM. Hexagonal ordering is favored based on entropy considerations [1, 2], and is commonly observed in the absence of a directing agent or a template. The histogram of the sizes of the Au nanocrystals (Fig. 3(d)) shows a mean particle size of $\sim 7.5 \mathrm{~nm}$, with a mean interparticle separation of $\sim 1.5 \mathrm{~nm}$. This distance can be attributed to the dodecanethiol molecules chemisorbed on the nanocrystal surface [46]. IR and Raman spectroscopy measurements confirmed the presence of the thiolate species (Fig. S-6 in the ESM). While the excess thiolate species may desorb at the annealing temperature of $250{ }^{\circ} \mathrm{C}$, that chemisorbed on the nanocrystal surface may remain [47] and induce the observed hexagonal ordering of the nanocrystals [48]. The average height of the stripes was found to be $\sim 60 \mathrm{~nm}$ based on atomic force microscopy (AFM) measurements, corresponding to $\sim 8$ nanocrystal layers (Fig. S-7 in the ESM).

Carrying out the second step at $120^{\circ} \mathrm{C}$ seems to be crucial. A higher temperature $\left(140{ }^{\circ} \mathrm{C}\right)$ leads to evaporation of the solvent inhibiting formation of the array (Fig. 2(f)). Lower temperatures, $80{ }^{\circ} \mathrm{C}$ or $100{ }^{\circ} \mathrm{C}$, also were not helpful (see Figs. 2(g) and 2(h), along with Fig. 4). Although superlattice formation is evident in Fig. 4, there are noticeable differences in particle

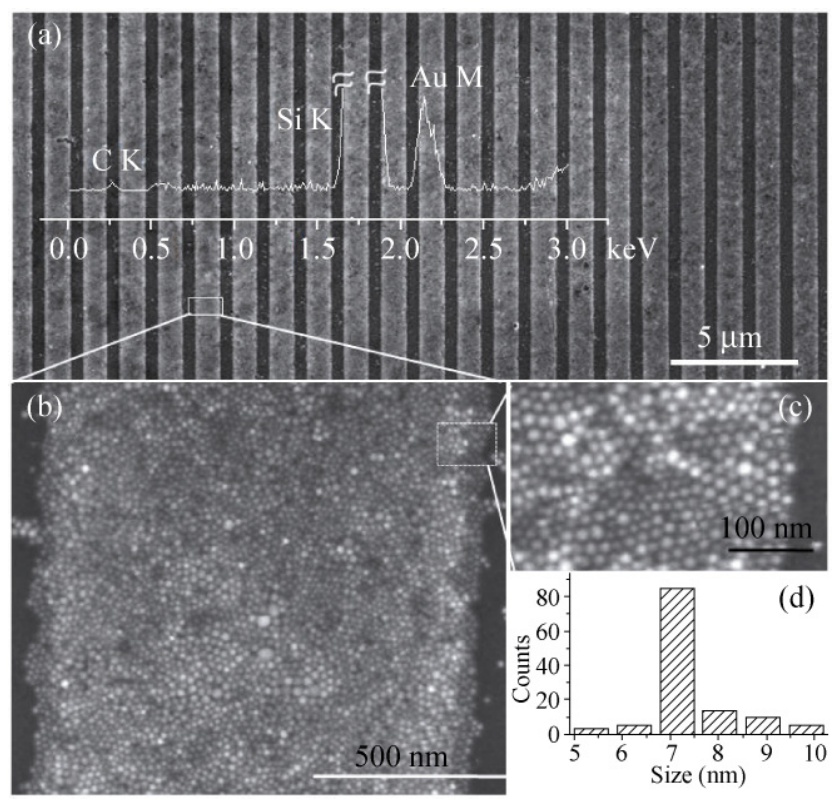

Figure 3 (a) SEM image showing the patterned Au nanocrystal superlattices formed by thermolysis at $250{ }^{\circ} \mathrm{C}$ for $30 \mathrm{~min}$, with the EDS data from the patterned region overlaid, with magnified views in (b) and (c), and (d) a histogram of the size of the Au nanocrystals from (c) 
size as well as extent of ordering. In the two-step preparation with the thiol introduced at $80^{\circ} \mathrm{C}$, the resulting stripes contain polydisperse nanocrystals, and hence, ordering in the microstripes is not quite uniform (Figs. 4(a) and 4(b)). The magnified view in Fig. 4(b) shows the size range to be 5 to $40 \mathrm{~nm}$ with an interparticle spacing of 3 to $5 \mathrm{~nm}$, as seen from the histogram in Fig. 4(c). On the other hand, introducing the thiol solution at $100{ }^{\circ} \mathrm{C}$ instead of at $80{ }^{\circ} \mathrm{C}$, led to nearly monosized and somewhat smaller (5-15 nm) $\mathrm{Au}$ nanocrystals (see Fig. 4(d)), with the interparticle spacing being $2-3 \mathrm{~nm}$. The extent of ordering is quite high owing to the monodispersity, which is a stringent condition for the formation of a superlattice. But, as can be seen from the magnified images in Fig. 4(b), there are domains where the superlattice is disrupted by intervening void regions.

The formation of the well ordered nanocrystal stripes shown in Fig. 3 is truly intriguing. At $120^{\circ} \mathrm{C}$, the solvent (toluene) is slightly above its boiling point and is expected to leave the microchannel rather quickly due to evaporation, causing less disruption of the Au nucleation sites. However, the presence of the

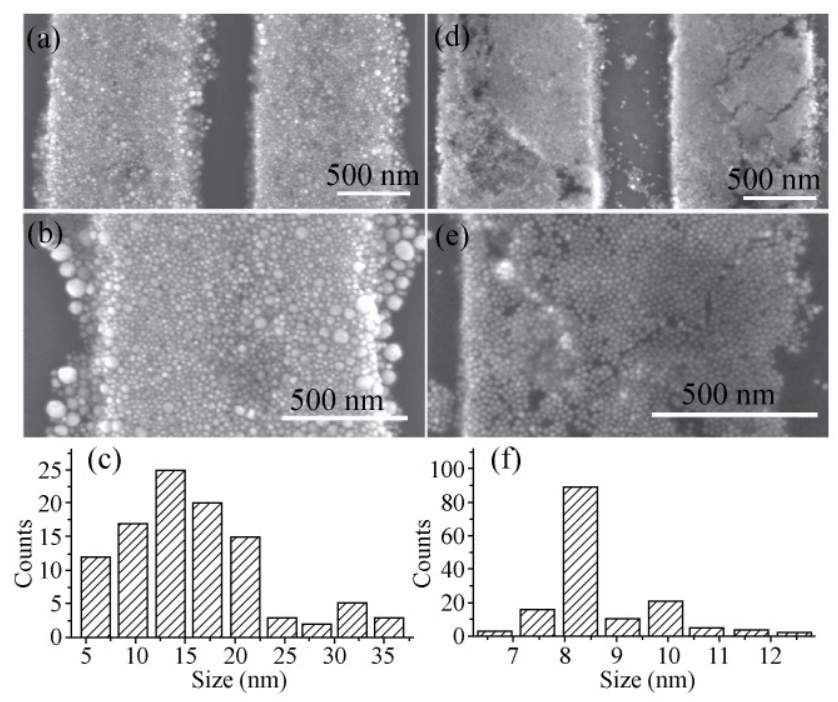

Figure 4 SEM images of patterned stripes of the Au nanocrystal superlattice formed by the introduction of the thiol (in the second step) at (a) $80{ }^{\circ} \mathrm{C}$ and (b) a magnified view of a single microstripe formed at $80{ }^{\circ} \mathrm{C}$; (d) the Au nanocrystal superlattice formed by the introduction of the thiol at $100{ }^{\circ} \mathrm{C}$ and (e) a magnified view of single microstripe formed at $100^{\circ} \mathrm{C}$. The corresponding histograms of particle size obtained with addition of the thiol at (c) $80{ }^{\circ} \mathrm{C}$ and (f) $100{ }^{\circ} \mathrm{C}$. The thermolysis temperature was $250{ }^{\circ} \mathrm{C}$ in each case solvent-even if for a short while-seems important. Replacing the thiol solution in toluene with the neat thiol, led to polydisperse nanocrystals along with a few elongated rod-like structures (Fig. S-8(a) in the ESM), instead of an ordered nanocrystal superlattice. The nature of the solvent also plays a role. When toluene was replaced by ethanol, we observed larger $\mathrm{Au}$ nanocrystals (Fig. S-8(b) in the ESM). Toluene is a good solvent for the Au precursor, and its presence in the microchannel seems to facilitate the reaction of the $\mathrm{Au}$ precursor with the thiol giving rise to an ordered lattice. Above $120^{\circ} \mathrm{C}$ however, introducing the solution is rather difficult as the whole setup becomes agitated, resulting in just a rudimentary network of particles (Fig. 2(f)).

Micromolding offers additional advantages. One may manipulate the fluid flow conditions inside the microchannels to achieve narrow feature sizes. Earlier, we have shown that starting with a stamp with nearly micron sized features, it is possible to directly imprint truly nanometric line patterns [49]. We term this process nanoentrapment molding, since under the pressure and heat treatment applied, the precursor is only deposited at the edges of the relief features. In order to pattern Au nanostripes via nanoentrapment molding, the PDMS stamp was kept on a cleaned Si wafer and an appropriate mass was applied on top amounting to a pressure of $450 \mathrm{~Pa}$ (see the schematic illustration in Fig. 5(a)). An SEM image of the patterned region (Fig. 5(b)) shows-in contrast to the images in Fig. 3-pairs of stripes of width $70 \mathrm{~nm}$, filled with nanocrystals. As seen in the magnified image of one stripe, the sizes of the crystal vary $(5-10 \mathrm{~nm})$ but the nanocrystals are tightly packed into thread-like features. The formation of such narrow stripe features from microchannels is typical of the nanoentrapment process [49]. In conformity with the nanochannel formation, we see pairs of parallel stripes $\sim 70 \mathrm{~nm}$ wide with internal separation of $\sim 430 \mathrm{~nm}$ and a distance of $\sim 990 \mathrm{~nm}$ between each pair (see Fig. 5(b)). Our method is much simpler and more effective than those based on solvent evaporation [39], since solvent evaporation from narrow channels (height or width $<100 \mathrm{~nm}$ ) is not trivial [50]. 


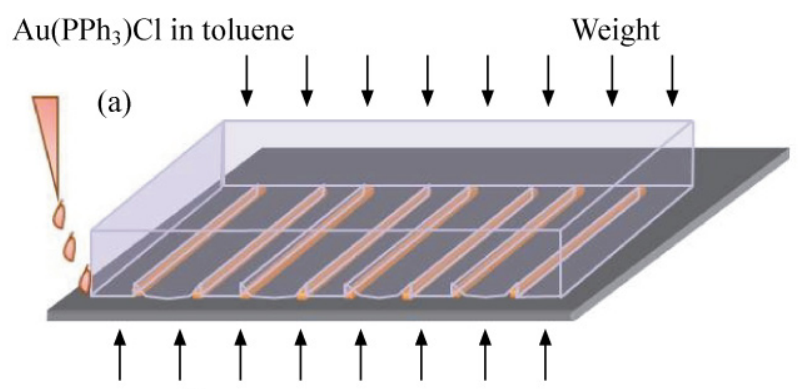

Heat at $120^{\circ} \mathrm{C}$, dodecanethiol $(1 \mathrm{mmol} / \mathrm{L})$ is introduced.

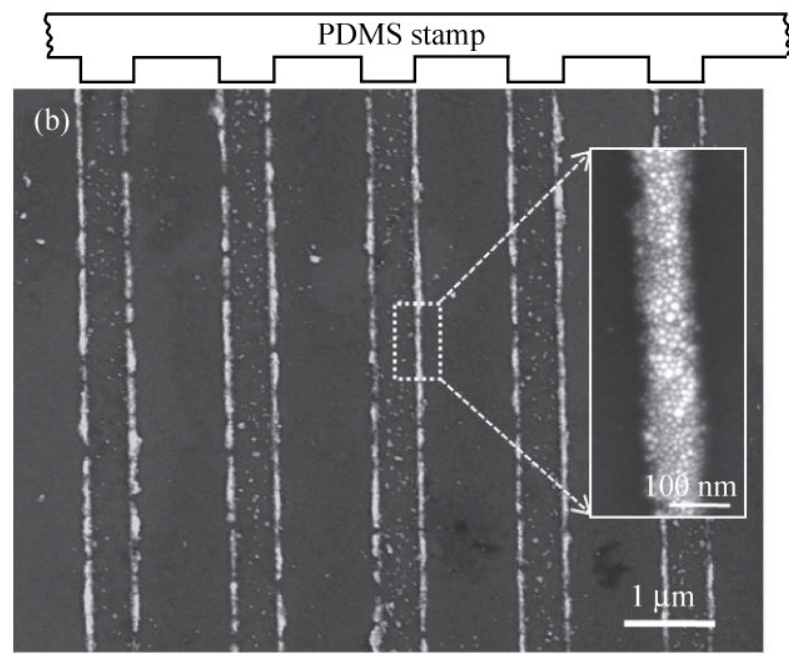

Figure 5 Nanoentrapment molding of $\mathrm{Au}$ nanocrystals. (a) Schematic illustration of the formation of nanochannels in the nanoentrapment molding process and (b) SEM micrograph of patterned Au nanocrystals formed on a Si substrate. A magnified view of an individual stripe is shown in the inset. Other conditions were similar to the process described in Fig. 3

\section{Conclusions}

We have developed a simple method to produce patterned superlattices of $\mathrm{Au}$ nanocrystals (with mean diameter of $7.5 \mathrm{~nm}$ ) synthesized in situ during micromolding using a PDMS stamp. The precursor leading to the formation of nanocrystals is $\mathrm{Au}(\mathrm{I})$ dodecanethiolate, which was synthesized in situ while molding, in order to address its limited solubility in common solvents. Au nanocrystals in the size range 5-10 nm were formed, with interparticle spacing of $\sim 1.5 \mathrm{~nm}$, in stripes which were $\sim 1080 \mathrm{~nm}$ wide with a spacing of $\sim 495 \mathrm{~nm}$, in conformity with the stamp geometry. By applying a gentle pressure while heating, we were able to induce nanoentrapment of the precursor and produce stripes which were only $\sim 70 \mathrm{~nm}$ wide. Clearly, the method is not limited to $\mathrm{Au}$ nor to the size range mentioned. However further experiments are required to optimize the conditions for other systems. Such patterned substrates may find applications as diffraction gratings, nanoscale interconnects, or even as active elements in devices relying on the exotic electronic properties arising from the ensemble nature of the nanocrystals. Patterning on flexible substrates is also a possibility.

\section{Acknowledgements}

The authors thank Professor C. N. R. Rao for his constant encouragement. Support from the Department of Science and Technology, India is gratefully acknowledged. B. R. thanks council for Scientific and Industrial Research (CSIR), India for financial assistance.

Electronic Supplementary Material: Supporting information (further details of the $\mathrm{Au}\left(\mathrm{PPh}_{3}\right) \mathrm{Cl}$ synthesis; thermal gravimetric analysis (TGA) measurements; SEM and AFM images; fast Fourier transform (FFT); Fourier transform infrared (FTIR) and Raman spectroscopy measurements for the $\mathrm{Au}$ nanocrystal stripes) are available in the online version of this article at http://dx.doi.org/10.1007/s12274-010-0014-8 and is accessible free of charge.

Open Access: This article is distributed under the terms of the Creative Commons Attribution Noncommercial License which permits any noncommercial use, distribution, and reproduction in any medium, provided the original author(s) and source are credited.

\section{References}

[1] Brust, M. Nanoparticle ensembles-nanocrystals come to order. Nat. Mater. 2005, 4, 364-365.

[2] Rao, C. N. R.; Kulkarni, G. U.; Thomas, P. J.; Edwards, P. P. Metal nanoparticles and their assemblies. Chem. Soc. Rev. 2000, 29, 27-35.

[3] Kinge, S.; Crego-Calama, M.; Reinhoudt, D. N. Self-assembling nanoparticles at surfaces and interfaces. ChemPhysChem 2008, 9, 20-42.

[4] Agrawal, V. V.; Varghese, N.; Kulkami, G. U.; Rao, C. N. 
R. Effects of changes in the interparticle separation induced by alkanethiols on the surface plasmon band and other properties of nanocrystalline gold films. Langmuir 2008, 24, 2494-2500.

[5] Salzemann, C.; Zhai, W.; Goubet, N.; Pileni, M. P. How to tune the $\mathrm{Au}$ internanocrystal distance in two-dimensional self-ordered superlattices. J. Phys. Chem. Lett. 2010, 1, 149-154.

[6] Brock, S. L. All-inorganic nanocrystal arrays. Angew. Chem. Int. Ed. 2009, 48, 7484-7486.

[7] Sun, S. H.; Murray, C. B.; Weller, D.; Folks, L.; Moser, A. Monodisperse FePt nanoparticles and ferromagnetic FePt nanocrystal superlattices. Science 2000, 287, 1989-1992.

[8] Teranishi, T. Fabrication and electronic properties of gold nanoparticle superlattices. C. R. Chimie 2003, 6, 979-987.

[9] Datta, S.; Janes, D. B.; Andres, R. P.; Kubiak, C. P.; Reifenberger, R. G. Molecular ribbons. Semicond. Sci. Tech. 1998, 13, 1347-1353.

[10] Chen, C. F.; Tzeng, S. D.; Chen, H. Y.; Lin, K. J.; Gwo, S. Tunable plasmonic response from alkanethiolate-stabilized gold nanoparticle superlattices: Evidence of near-field coupling J. Am. Chem. Soc. 2008, 130, 824-825.

[11] Berven, C. A.; Wybourne, M. N.; Longstreth, L.; Hutchison, J. E. Nanoparticle based Boolean logic. Physica E 2003, 19, 246-250.

[12] Collier, C. P.; Saykally, R. J.; Shiang, J. J.; Henrichs, S. E.; Heath, J. R. Reversible tuning of silver quantum dot monolayers through the metal-insulator transition. Science 1997, 277, 1978-1981.

[13] Markovich, G.; Collier, C. P.; Henrichs, S. E.; Remacle, F.; Levine, R. D.; Heath, J. R. Architectonic quantum dot solids. Acc. Chem. Res. 1999, 32, 415-423.

[14] Black, C. T.; Murray, C. B.; Sandstrom, R. L.; Sun, S. H., Spin-dependent tunneling in self-assembled cobalt-nanocrystal superlattices. Science 2000, 290, 1131-1134.

[15] Warner, M. G.; Hutchison, J. E. Linear assemblies of nanoparticles electrostatically organized on DNA scaffolds. Nat. Mater. 2003, 2, 272-277.

[16] Shibu, E. S.; Habeeb Muhammed, M. A.; Kimura, K.; Pradeep, T. Fluorescent superlattices of gold nanoparticles: A new class of functional materials. Nano Res. 2009, 2, 220-234.

[17] Pileni, M. P. Supracrystals of inorganic nanocrystals: An open challenge for new physical properties. Acc. Chem. Res. 2008, 41, 1799-1809.

[18] Hamann, H. F.; Woods, S. I.; Sun, S. Direct thermal patterning of self-assembled nanoparticles. Nano Lett. 2003, $3,1643-1645$.
[19] Glass, R.; Arnold, M.; Blummel, J.; Kuller, A.; Moller, M.; Spatz, J. P. Micro-nanostructured interfaces fabricated by the use of inorganic block copolymer micellar monolayers as negative resist for electron-beam lithography. Adv. Funct. Mater. 2003, 13, 569-575.

[20] Corbierre, M. K.; Beerens, J.; Lennox, R. B. Gold nanoparticles generated by electron beam lithography of gold(I)-thiolate thin films. Chem. Mater. 2005, 17, 5774-5779.

[21] Corbierre, M. K.; Beerens, J.; Beauvais, J.; Lennox, R. B. Uniform one-dimensional arrays of tunable gold nanoparticles with tunable interparticle distances. Chem. Mater. 2005, 18, 2628-2631.

[22] Werts, M. H. V.; Lambert, M.; Bourgoin, J. P.; Brust, M. Nanometer scale patterning of Langmuir-Blodgett films of gold nanoparticles by electron beam lithography. Nano Lett. 2002, 2, 43-47.

[23] Lohau, J.; Friedrichowski, S.; Dumpich, G.; Wassermann, E. F. Electron-beam lithography with metal colloids: Direct writing of metallic nanostructures. J. Vac. Sci. Technol. B 1998, 16, 77-79.

[24] Hoffmann, P.; Benassayag, G.; Gierak, J.; Flicstein, J.; Maarstumm, M.; Vandenbergh, H. Direct writing of gold nanostructures using a gold-cluster compound and a focused-ion beam. Appl. Phys. 1993, 74, 7588-7591.

[25] Kim, H.; Kim, J.; Yang, H. J.; Suh, J.; Kim, T.; Han, B. W.; Kim, S.; Kim, D. S.; Pikhitsa, P. V.; Choi, M. Parallel patterning of nanoparticles via electrodynamic focusing of charged aerosols. Nat. Nanotechnol. 2006, 1, 117-121.

[26] Lee, J. P.; Kim, E. U.; Koh, H. D.; Kang, N. G.; Jung, G. Y.; Lee, J. S. The fabrication of nanopatterns with $\mathrm{Au}$ nanoparticles - embedded micelles via nanoimprint lithography. Nanotechnology 2009, 20, 365301.

[27] Santhanam, V.; Andres, R. P. Microcontact printing of uniform nanoparticle arrays. Nano Lett. 2004, 4, 41-44.

[28] Yun, S. H.; Sohn, B. H.; Jung, J. C.; Zin, W. C.; Ree, M.; Park, J. W. Micropatterning of a single layer of nanoparticles by lithographical methods with diblock copolymer micelles. Nanotechnology 2006, 17, 450-454.

[29] Kraus, T.; Malaquin, L.; Schmid, H.; Riess, W.; Spencer, N. D.; Wolf, H. Nanoparticle printing with single-particle resolution. Nat. Nanotechnol. 2007, 2, 570-576.

[30] Chen, J.; Mela, P.; Muller, M.; Lensen, M. C. Microcontact deprinting: A technique to pattern gold nanoparticles. ACS Nano 2009, 3, 1451-1456.

[31] Cavallini, M.; Biscarini, F. Nanostructuring conjugated materials by lithographically controlled wetting. Nano Lett. 2003, 3, 1269-1271.

[32] Lu, N.; Chen, X. D.; Molenda, D.; Naber, A.; Fuchs, H.; Talapin, D. V.; Weller, H.; Muller, J.; Lupton, J. M.; 
Feldmann, J.; Rogach, A. L.; Chi, L. F. Lateral patterning of luminescent CdSe nanocrystals by selective dewetting from self-assembled organic templates. Nano Lett. 2004, 4, 885-888.

[33] Cheng, W. L.; Park, N. Y.; Walter, M. T.; Hartman, M. R.; Luo, D. Nanopatterning self-assembled nanoparticle superlattices by moulding microdroplets. Nat. Nanotechnol. 2008, 3, 682-690.

[34] Cheng, W. L.; Campolongo, M. J.; Cha, J. J.; Tan, S. J.; Umbach, C. C.; Muller, D. A.; Luo, D. Free-standing nanoparticle superlattice sheets controlled by DNA. Nat. Mater. 2009, 8, 519-525.

[35] Gates, B. D.; Xu, Q.; Love, J. C.; Wolfe, D. B.; Whitesides, G. M. Unconventional nanofabrication. Ann. Rev. Mater. Res. 2004, 34, 339-372.

[36] Kim, E.; Xia, Y.; Whitesides, G. M. Micromolding in capillaries: Applications in materials science. J. Am. Chem. Soc. 1996, 118, 5722-5731.

[37] Martin, C. P.; Blunt, M. O.; Pauliac-Vaujour, E.; Stannard, A.; Moriarty, P.; Vancea, I.; Thiele, U. Controlling pattern formation in nanoparticle assemblies via directed solvent dewetting. Phys. Rev. Lett. 2007, 99, 116103.

[38] Rabani, E.; Reichman, D. R.; Geissler, P. L.; Brus, L. E. Drying-mediated self-assembly of nanoparticles. Nature 2003, 426, 271-274.

[39] Akey, A.; Lu, C.; Yang, L.; Herman, I. P. Formation of thick, large-area nanoparticle superlattices in lithographically defined geometries. Nano Lett. 2010, 10, 1517-1521.

[40] Boisselier, E.; Astruc, D. Gold nanoparticles in nanomedicine: Preparations, imaging, diagnostics, therapies and toxicity. Chem. Soc. Rev. 2009, 38, 1759-1782.

[41] Murphy, C. J.; Gole, A. M.; Stone, J. W.; Sisco, P. N.; Alkilany, A. M.; Goldsmith, E. C.; Baxter, S. C. Gold nanoparticles in biology: Beyond toxicity to cellular imaging. Acc. Chem. Res. 2008, 41, 1721-1730.

[42] Rosi, N. L.; Giljohann, D. A.; Thaxton, C. S.; Lytton-Jean, A. K. R.; Han, M. S.; Mirkin, C. A. Oligonucleotidemodified gold nanoparticles for intracellular gene regulation. Science 2006, 312, 1027-1030.

[43] For instance in the Brust method, a complex, $\mathrm{AuCl}_{4}^{-}$tetraoctylammonium bromide-alkanethiol serves as precursor for $\mathrm{Au}$ nanocrystals with $\mathrm{NaBH}_{4}$ as the reducing agent.

[44] Carotenuto, G.; Martorana, B.; Perlo, P. B.; Nicolais, L. A universal method for the synthesis of metal and metal sulfide clusters embedded in polymer matrices. J. Mater. Chem. 2003, 13, 2927-2930.

[45] Nakamoto, M.; Yamamoto, M.; Fukusumi, M. Thermolysis of gold(I) thiolate complexes producing novel gold nanoparticles passivated by alkyl groups. Chem. Commun. 2002, 1622-1623.

[46] Thomas, P. J.; Kulkarni, G. U.; Rao, C. N. R. An investigation of two-dimensional arrays of thiolized $\mathrm{Pd}$ nanocrystals. J. Phys. Chem. B 2000, 104, 8138-8144.

[47] Ristau, R.; Tiruvalam, R.; Clasen, P. L.; Gorskowski, E. P.; Harmer, M. P.; Kiely, C. J.; Hussain, I.; Brust, M. Electron microscopy studies of the thermal stability of gold nanoparticle arrays. Gold Bull. 2009, 42, 133-143.

[48] Sidhaye, D. S.; Prasad, B. L. V. Melting characteristics of superlattices of alkanethiol-capped gold nanoparticles: The "excluded" story of excess thiol. Chem. Mater. 2010, 22, 1680-1685.

[49] Radha, B.; Kulkarni, G. U. A modified micromolding method for sub-100 nm direct patterning of Pd nanowires. Small 2009, 5, 2271-2275.

[50] Sparreboom, W.; van den Berg, A.; Eijkel, J. C. T. Principles and applications of nanofluidic transport. Nat. Nanotechnol. 2009, 4, 713-720. 